\title{
Early R Wave Transition by ECG Finding
}

National Cancer Institute

\section{Source}

National Cancer Institute. Early R Wave Transition by ECG Finding. NCI Thesaurus. Code C102628.

An electrocardiographic finding where the amplitude of the $\mathrm{R}$ wave becomes greater than the amplitude of the $S$ wave in the QRS complex at an unusually early point in the precordial leads, usually in leads V1 or V2. (CDISC) 